\title{
Numerical Modelling of Riveted Railway Bridge Connections for
}

\section{Fatigue Evaluation}

\author{
Boulent M. Imam*, Timothy D. Righiniotis and Marios K. Chryssanthopoulos \\ School of Engineering, University of Surrey, Guildford, GU2 7XH, United Kingdom \\ ${ }^{*}$ Corresponding Author. Tel: +44-1483-686652; Fax: +44-1483-450984: Email address: \\ b.imam@surrey.ac.uk; Postal address: School of Engineering (C5), University of Surrey, Guildford, \\ Surrey, GU2 7XH, United Kingdom
}

\begin{abstract}
Past experience has shown that stringer-to-cross-girder connections in riveted railway bridges are susceptible to fatigue cracking. This fatigue damage is caused by secondary stresses, which develop in the different components of the connection. For this reason, more detailed analysis techniques are needed to capture this type of behaviour. In this paper, a finite element (FE) model of a typical riveted railway bridge is developed by incorporating the detailed local geometry of a stringer-to-cross-girder connection into the global bridge model. Prior to the development of this model, benchmark FE studies are carried out on a double-lap joint and the results are presented in terms of stress concentration factors and stress gradients. Further verification studies are carried out on a local bridge connection FE model, in terms of its rotational stiffness. Following this investigation, a refined FE model of the bridge is analysed under the passage of a freight train. Principal stress histories at different components of the connection are obtained, which are then combined with the plain material S-N curve, in order to identify the most fatigue-critical locations of the connection. These are identified as being the rivet holes and, in some cases, the angle fillet. By considering different rivet clamping stresses and different rivet defect scenarios it is found that the most damaging effects are caused by the presence of clearance between the rivet shank and the hole, and the loss of a rivet. The rivet clamping stress is also found to affect fatigue damage considerably.
\end{abstract}

Keywords: Finite element method; riveted bridges; fatigue damage; S-N method.

\section{Introduction}

During the past few decades, different research initiatives, focusing on the fatigue performance of riveted railway bridges, have been carried out. In view of the large number of these bridges in North America and 
Europe, as well as their considerable age, which in many cases already exceeds 100 years, different methodologies for their fatigue assessment have been developed [1,2]. Most of these efforts have aimed at estimating the remaining fatigue lives of the primary bridge members, such as stringers [3-6], crossgirders [4,6-8], truss diagonals [3] or truss hangers [4-6], employing simple structural bridge models with beam elements. Identification of the fatigue-critical members was usually carried out empirically.

However, most of the fatigue damage that has been reported on riveted bridges has been observed on the riveted connections between the primary members. This damage has been attributed to secondary effects such as out-of-plane deformations [9,10]. For this reason, refined finite element (FE) models of riveted bridge connections, consisting of an assembly of a few stringers, cross-girders and the connection components (angle, rivets) have been investigated in the recent past [11,12]. Stress analysis of these models, which were carried out under single point loads application, have revealed that the angle fillet and the rivet head-to-shank junction are fatigue-critical locations where cracks may initiate. While the criticality of these locations has been confirmed through full-scale experiments on bridge parts [13], no quantitative estimates of fatigue damage based on full train stress histories in conjunction with detailed connection models have been reported so far.

In a previous study [14], the FE model of a typical short-span, plate girder, riveted railway bridge was constructed using exclusively shell elements and analysed in order to determine the most fatigue-critical connections of the bridge. This bridge model, which is shown together with its relevant dimensions in Fig. 1, was used to produce stress histories under historical and present day train traffic. By assuming that the connections were fully fixed and considering the Miner damage, the inner stringer-to-cross-girder connections were found to be the most highly-damaged, as indicated in Fig. $1[14,15]$. The fixed connection assumption made in [14] has been shown to result in the highest fatigue damage [16]. Furthermore, previous studies have demonstrated that this assumption results in stress histories, which are in better agreement with field measurements in similar bridges [17].

Although the type of modelling used in $[14,16]$ permits ranking of the connections in terms of their fatigue criticality, it does not take into account the local connection geometry. However, fatigue cracks may develop at different locations in the connection such as holes, rivets and angle clips. These 'hot 
spots' are by virtue of their local geometry stress raisers, which naturally promote fatigue crack growth. Depending on the location of these hot spots in a connection, the fatigue life may vary considerably.

For these reasons, in this paper, the previous global bridge model shown in Fig. 1 is enhanced at the location of one of the most fatigue-critical stringer-to-cross-girder connections. The full connection geometry with its detailed characteristics is taken into account in this model, which is referred to in the sequel as the 'global-local' model. However, three-dimensional (3-D), FE modelling of a riveted connection involves not only its geometrical representation, but also has to take into account various features such as contact and friction between the connecting parts as well as the clamping forces in the rivets. Prior to the development of such a complex model, a simple double-lap, riveted joint, incorporating these features, is investigated here using the FE method. The results of this benchmark study are presented in the form of stress concentration factors (SCF) and stress gradients around the rivet hole and are compared with published results. Further to this study, a 3-D FE model of a riveted bridge connection consisting of an assembly of a cross-girder and two stringers is also developed. Comparisons of its rotational stiffness with the results on similar types of connection presented elsewhere are carried out.

Following these benchmark studies, the local connection geometry is incorporated in the global bridge model shown in Fig. 1. The analyses of the global-local model are carried out under the passage of a BS 5400 [18] freight train over the bridge. Principal stress histories are obtained at various locations in the connection and fatigue damage is estimated using the plain material S-N curve and Miner's rule. In doing so, the different components of the connection are ranked according to their S-N-calculated fatigue damage. The effect of rivet clamping force and various rivet defect scenarios on fatigue damage is investigated, and fatigue crack initiation patterns from the hot spots are presented.

\section{Benchmark Studies}

\subsection{Riveted Double-Lap Joint}

The FE model of the double-lap joint is shown in Fig. 2(a) together with its dimensions. This joint, which was investigated by Carter [19], consists of two outer plates with a thickness of $9.5 \mathrm{~mm}$ each, a middle plate with a thickness of $11.1 \mathrm{~mm}$ and a single $25.4 \mathrm{~mm}$ diameter rivet. The top and bottom plates are 
translationally fixed on their right end faces B1-B2 and C1-C2, respectively. The load is applied on the left face of the middle plate as a uniform pressure $P$. In order to enable comparisons with published results, a very low clamping stress of $1 \mathrm{MPa}$ is considered in the analysis. The FE mesh of the double-lap joint consists of approximately 11600 elements and 45000 degrees of freedom.

The FE analyses are performed with the commercial FE-code ABAQUS [20]. Contact between the individual parts of the assembly (plate-to-plate, rivet head-to-plate and rivet-to-hole) is modelled using contact pairs and the master-slave surface algorithm of ABAQUS. 8-noded brick elements with full integration are used to model the plates and rivet. A Coulomb friction model with an assumed coefficient of friction of 0.3 is considered in the analysis. The surfaces of the rivet head are forced to remain in contact with the plates throughout the analysis. The clamping stress in the rivet is modelled using the *PRE-TENSION SURFACE* option of ABAQUS at the mid-length location of the rivet. The plates and rivet are assumed to behave elastically with a Young's Modulus of $200 \mathrm{GPa}$ and a Poisson's ratio of 0.3. The FE analysis is performed in two steps. The clamping stress in the rivet is applied during the first step. In the second step the external load is applied in addition to the clamping stress. Following the recommendations made in [21,22], 4 layers of brick elements are used here through the thickness of each plate and 24 elements around the perimeter of the rivet.

The results obtained from the analysis of the double-lap joint are presented here in the form of SCF, stress distributions and stress gradients at the edge of the hole. A total of six points, two on each plate, at their top and bottom surfaces, are investigated as shown in Fig. 2(b). Points F and G correspond to the top plate, points $\mathrm{H}$ and I to the middle plate and points $\mathrm{J}$ and $\mathrm{K}$ to the bottom plate. The SCF are compared with values given in [23], where 3-D FE analyses of a plate with a hole subjected to loading conditions such as remote tension, remote bending and wedge loading were carried out. Wedge loading may be assumed to be representative of a pin bearing on the hole. The compound SCF $K_{p}$, arising from the superposition of wedge and external tension loading, may be approximated as [23]

$$
K_{p}=\frac{K_{w}+(r / w) K_{t}}{2}
$$

where $K_{w}$ and $K_{t}$ are the SCF for wedge and remote tension loading, respectively, $r$ is the hole radius and $w$ is the plate half-width. The SCF for wedge loading is defined as 


$$
K_{w}=\frac{\sigma_{11}}{P^{\prime} / 2 r t}
$$

where $\sigma_{11}$ is the longitudinal stress at the point of consideration, $P^{\prime}$ is the wedge load $(=P \times 2 w \times t)$ and $t$ is the thickness of the relevant plate. $K_{t}$ is defined in the usual way as

$$
K_{t}=\frac{\sigma_{11}}{P}
$$

Stress concentration equations for $K_{t}$ and $K_{w}$ were developed in [23] by fitting the FE results to a doubleseries polynomial equation in the form of

$$
K_{n}=\sum_{i=0}^{4} \sum_{j=0}^{4} \alpha_{i j}(r / t)^{i}(z / t)^{2 j}
$$

where $n=t$ for remote tension and $n=w$ for wedge loading and $z$ is the depth measured along the thickness of the plates.

Table 1 compares, at different locations indicated in Fig. 2(b), the SCF obtained from the present FE analysis with $K_{p}$. Reasonable overall agreement may be seen between the two sets of results with the maximum difference being 25\% (top/bottom plate). The discrepancies between these results are smaller (approximately 20\%) in the case of the middle plate. These differences observed between the two sets of results may be attributed to the fact that the pin was not modelled explicitly in [23], as was done in the present FE analysis. Instead, pin loading was represented by applying a normal pressure loading to the hole, having a cosine distribution throughout the plate thickness [23].

Further to the SCF results, stress gradients at the hole edge are also compared with published results. The stress gradient at a notch is perhaps of greater importance than the SCF because fatigue crack initiation and the crack propagation process depend primarily on the level of loading experienced ahead of the crack tip [24]. Thus, a lower stress gradient implies a higher average stress acting over a small region ahead of the notch and is, therefore, more critical.

Fig. 3 shows the longitudinal stress distribution, normalised by the remote stress $P$ in each plate, along the width of each plate from the edge of the hole $(x / 2 w=0.165)$ up to the outer edge of the plate $(x / 2 w=0.5)$. Three sets of curves are obtained corresponding to the points shown in Fig. 2(b). The theoretical distribution for an infinite plate with a central empty hole [25] is also shown in the figure. According to 
the results shown in Fig. 3, a crack would be expected to initiate at the edge of the hole in the middle plate, at the interface between the plates. This type of damage has been observed in fatigue tests carried out on steel riveted lap joints [19,26]. Moreover, it can also be seen in Fig. 3 that a hole containing a rivet results in a higher SCF than an empty hole and is, therefore, more fatigue-critical. This is due to the effect of rivet bearing which is the most important source of stress concentrations in rivet-loaded holes [19].

The relative stress gradient at edge of the hole $(x / 2 w=0.165)$ can be calculated as [27]

$Q=\frac{1}{\sigma_{\max }} \frac{d \sigma_{11}}{d x}$

where $\sigma_{\max }$ is the peak stress. By using the theoretical stress distribution [25], Fuchs and Stephens derived an expression for the relative stress gradient at the edge of the hole in an infinite plate, which is given as [27]

$Q=-2.33 / r$

In [28], a different expression for $Q$ was given as

$$
Q=-\left(2+\frac{1}{S C F}\right) \frac{1}{r}
$$

On the other hand, the values obtained from [29] are for the case of finite width plates with a central hole. These values were obtained by using a number of different exact analytical solutions for the stresses in the neighbourhood of a circular hole in conjunction with Eq. (5).

Table 2 compares the relative stress gradients estimated from the FE results with different values obtained from the literature. As can be seen, the FE results agree well with the results published in the literature with the maximum difference being of the order of 50\%. The differences observed between the FE and the analytical results may be attributed to the fact that the latter are used for the case of a plate with an empty hole. The lower stress gradients obtained by the FE analysis confirm the higher criticality of a rivet-loaded hole when compared to an empty hole.

Overall, the FE results obtained from the analysis of the double-lap joint showed good agreement with theoretical results obtained from the literature in terms of both SCF and stress gradients.

\subsection{Local bridge connection model}


Here, a local riveted bridge connection model is developed using the modelling techniques discussed previously. The refined connection model, which consists of an assembly of a cross-girder and two stringers, is shown in Fig. 4. The two ends of the cross-girder and the end of one stringer are modelled as fixed. The remaining stringer is modelled as a cantilever. The connection consists of four $76 \times 76 \times 12.6$ $\mathrm{mm}$ angles, each riveted to the stringer and cross-girder webs using two and three $19 \mathrm{~mm}$ rivets, respectively. All the connection angles, the rivets and part of the cross-girder and the stringers are modelled by using 8-noded brick elements with full integration. The remaining part of the assembly is modelled using 8-noded shell elements. A shell-to-solid interface is used for the transition from the shell elements away from the connection to the brick elements. Different clamping stresses, assumed to be equal in all the rivets, were considered. These ranged between 50 to $200 \mathrm{MPa}$, which are in broad agreement with field observations [30,31]. A Young's Modulus of 200 GPa, Poisson's ratio of 0.3 and linear elastic behaviour is assumed for the FE analyses. A point load $F_{a}$ is applied on one of the stringers at an arbitrary distance from the connection as shown in Fig. 4 and is increased in steps in order to investigate the moment-rotation behaviour of the connection.

The moment-rotation behaviour of the connection is shown in Fig. 5 for different values of the rivet clamping stress (50-200 MPa) labelled as C50 to C200 in the legend. The rotation reported in the figure is the relative rotation of the stringer with respect to the cross-girder, as shown in the inset of Fig. 5. The initial slopes of the moment-rotation curves (up to approximately $0.001 \mathrm{rad}$ ) are slightly higher than the slopes of the remaining part of the curves. This may be attributed to the effect of friction which is taken into account in the FE model by defining a coefficient of friction of 0.3 between the surfaces that are in contact. The rotational stiffness of the connection can be seen to be only marginally affected by the rivet clamping stress. This was also observed in [12] through FE analyses of a stringer-to-cross-girder connection.

Table 3 compares the rotational stiffness of the connection, corresponding to a $50 \mathrm{MPa}$ and $200 \mathrm{MPa}$ rivet clamping stress with values published in the literature. With the exception of [32] and [36], which considered stringer-to-cross-girder connections, the remaining published analytical models were developed in order to represent the rotational stiffness of double-angle, beam-to-column connections. In [32-34], the connection angle was modelled as a series of beam elements and it was assumed that it is 
fixed at the centreline of the fasteners and that the column flange to which the beam is connected is rigid. In [35], the part of the angle connected to the column flange was modelled as a thick plate. In [36], which was based on a number of tests carried out on various connections, the connection stiffness was related to the number and size of the rivets. The large differences observed in Table 3 can be attributed to the different assumptions used in the analytical models. The results of the present FE model can be seen to lie below the analytical results but considerably higher than the prediction of the test-based model. The stringer-to-cross-girder connection behaviour predicted by the FE analysis is more flexible when compared to the analytical models for beam-to-column connections. In the case of stringer-to-cross-girder connections, the cross-girder web to which the stringer is connected is more flexible thus resulting in a lower rotational stiffness than the beam-to-column connections where the column flange was assumed rigid. Another reason for the high rotational stiffnesses predicted by the analytical models is the assumption that the leg of the angle connected to the column flange is fixed at the centreline of the fasteners. It would appear that the angle is only partially fixed at that location. The thick plate representation in [35] can be seen to predict an even more rigid connection behaviour than the others resulting in the highest rotational stiffness value.

\section{Global-Local Fatigue Analysis}

\subsection{Model Description}

Details on the global bridge model (Fig. 1), which was constructed using shell elements, may be found in [14]. Fatigue studies [14] identified the inner stringer-to-cross-girder connections as the most fatiguecritical. Here, the local FE model of Fig. 4 is incorporated in the global model in one of these critical locations as shown in Fig. 6. This type of modelling permits fatigue damage calculations to be carried out for the individual components of the connection (angles, rivets). Furthermore, the global-local model allows the local flexibility of the connection to be accounted for. A close-up view of the FE model at and near the connection region is shown in Fig. 7 together with the nomenclature that will be used to identify its different parts. The entire global-local FE model consists of approximately 67000 brick elements and 20000 shell elements. Different values of rivet clamping stress, assumed to be the same in all the rivets, are investigated, ranging from 50 to $200 \mathrm{MPa}$. FE analyses are carried out assuming a Young's Modulus of $200 \mathrm{GPa}$, a Poisson's ratio of 0.3 and linear elastic material behaviour. 


\subsection{Bridge Loading}

The bridge is loaded with the BS 5400 train No 7 [18], which consists of an engine car in front followed by ten similar wagons. This train has a maximum axle load of 25 tons. For the purposes of the analyses, the train is traversed in $1 \mathrm{~m}$ steps over one track of the bridge, as shown in Fig. 6, up to the point of load repetition, which is caused by the passage of the same wagons. Axle loads are applied directly on the top flange of the stringers neglecting the beneficial effect of any load spread due to the rails and sleepers. However, the self-weight of the bridge members and the superimposed dead load due to the sleepers and rails are taken into account in the FE model. The loads are applied quasi-statically and no dynamic amplification is considered.

\subsection{Fatigue Damage Calculation}

The damage caused by the passage of the train is calculated by first converting the FE principal stress histories at various connection hot spots into stress range blocks using the rainflow counting method and then applying Miner's rule. A design (mean minus two standard deviations) S-N curve, related to wrought-iron plain material [37], is used for the calculation of fatigue damage. The fatigue limit for this detail class is equal to $65 \mathrm{MPa}$ at $10^{7}$ cycles and the slope of the S-N curve above the fatigue limit is equal to $1 / 4$. A two-slope S-N curve is used as proposed by BS 5400 [18] for variable amplitude loading. The change of slope from $1 / m$ to $1 /(m+2)$ occurs at $10^{7}$ cycles. Accordingly, the fatigue damage for a single train passage will be given as

$$
D=\underbrace{\sum_{i=1}^{k_{1}} \frac{n_{i}}{10^{7}}\left[\frac{\left(\Delta \sigma_{p}\right)_{i}}{\Delta \sigma_{0}}\right]^{m}}_{\text {for }\left(\Delta \sigma_{p}\right)_{i} \geq \Delta \sigma_{0}}+\underbrace{\sum_{j=1}^{k_{2}} \frac{n_{j}}{10^{7}}\left[\frac{\left(\Delta \sigma_{p}\right)_{j}}{\Delta \sigma_{0}}\right]^{m+2}}_{\text {for }\left(\Delta \sigma_{p}\right)_{j} \leq \Delta \sigma_{0}}
$$

where $\left(\Delta \sigma_{p}\right)_{i}$ and $\left(\Delta \sigma_{p}\right)_{j}$ are the $i^{\text {th }}$ and $j^{\text {th }}$ principal stress ranges, $n_{i}$ and $n_{j}$ are the number of cycles in each $\left(\Delta \sigma_{p}\right)_{i}$ and $\left(\Delta \sigma_{p}\right)_{j}$, and $k_{l}$ and $k_{2}$ represent the number of different stress range blocks respectively above or below the fatigue limit $\Delta \sigma_{0}$.

\subsection{Rivet Defect Scenarios}

In addition to different rivet clamping stresses (50 to $200 \mathrm{MPa}$ ), the effect of different rivet defect scenarios on fatigue damage is also investigated. These scenarios are considered for rivet 1 (see Fig. 7), based on field observations, which have shown that fatigue damage in stringer-to-cross-girder 
connections is more likely to occur in either the top or the bottom rivets [32]. The scenarios, which are considered here are (i) loss of clamping force, (ii) complete loss of the rivet, (iii) partial loss of the rivet head, (iv) offset of the rivet head and (v) presence of a clearance between the rivet and its hole.

Loss of clamping stress in a rivet may be gradual over a number of years through relaxation of the rivet due to vibrations and fretting between the connection components [32]. Moreover, tensile overloads in the rivets may also cause local yielding in the rivet head-to-shank junction leading to a partial or even complete loss of clamping force. The complete loss of a rivet, which is modelled by simply removing the rivet from the FE model, may result from its fatigue failure. A small rivet head may be caused by poor pressing during the riveting process or due to material loss caused by corrosion. For the purposes of the present study, a smaller rivet head of $12 \mathrm{~mm}$ radius, as compared to the $16 \mathrm{~mm}$ radius of the original rivet head, is assumed for rivet 1 . Rivet head offset may result from eccentric punching during assembly of the connection. In the present study, a $3 \mathrm{~mm}$ eccentricity of the rivet 1 head towards the outer edge of the angle is assumed. Clearances between the rivet and its hole may come about through insufficient heating and/or punching during the riveting process or through material loss from corrosion of the rivet shank. For the purposes of the analyses, a $0.5 \mathrm{~mm}$ clearance between rivet 1 and its corresponding hole is examined.

\subsection{Results and Discussion}

The FE analyses of the global-local model under train loading have identified several regions of high stress concentration in the connection. In general, the positions of these highly-stressed (hot spot) regions vary as the train is traversed over the bridge. Despite this, hot spots were typically located along the connection angle fillet, along the circumference of the rivet holes on the face of the connection angle which is in contact with the cross-girder and the stringer webs, and on the rivets around their circumference at the head-to-shank junction.

The fatigue damage was calculated using Eq. (8), for a number of points in the highly-stressed regions. Based on these calculations the most fatigue critical hot spots are shown in Fig. 8. Fig. 9 depicts the single train fatigue damage of the hot spots shown in Fig. 8, for different clamping stresses. As can be seen in Fig. 9, with the exception of the angle fillet location, a higher rivet clamping stress results in 
lower fatigue damage. Overall, Fig. 9 demonstrates that the most damaged regions in the connection are holes 4 and 5. On the other hand, the least damaged components are the rivets. By contrast, the angle fillet may become the most fatigue-critical location when rivet clamping is large.

Fig. 10 presents fatigue damage corresponding to the rivet defects itemised in Section 3.4. The results for a $100 \mathrm{MPa}$ rivet clamping stress and no rivet defects are also shown, by way of comparison. As can be seen, holes remain the most fatigue-critical locations, irrespective of defect. Again, the least damaged parts of the connection are the rivets. Furthermore, loss of rivet 1 and rivet clearance in hole 1 appear to shift the damage from holes 4 and 5 to hole 2, which is adjacent to the defective region. In the case of rivet loss, it can be seen in Fig. 10 that the fatigue damage of the hole from which the rivet is lost (hole 1) reduces to almost negligible levels which can be attributed to the absence of bearing of the rivet on the hole. Furthermore, defects associated with loss and offset of the rivet head and loss of clamping stress are seen not to be that significant resulting only in small changes in the fatigue damage of the connection. The results shown in Fig. 10 demonstrate that defects in any one of the rivets influence mostly its adjacent locations. Consequently, these changes appear to be less significant in the angle fillet and rivets/holes 4 and 5.

Fig. 11(b) shows the side of the angle leg, which is in contact with the cross-girder web, together with the hot spots at the angle holes identified in Fig. 9. Fig. 11(c) depicts the vector plots of the maximum principal stress indicating its direction, for a particular load step and assuming a 100 MPa rivet clamping stress. Finally, Fig. 11(a) shows possible crack initiation patterns at the region near each hot spot. The direction of the maximum principal stress at each of these hot spots was found to rotate as the train was traversed over the bridge, but not by a considerable amount (maximum of $30^{\circ}$ ). The directions indicated in Fig. 11(c) may, therefore, be thought of representing an average principal stress direction for a train passage. It can be seen in Fig. 11(c) that the maximum principal stresses act along an average direction which is approximately normal to the hole radius passing through the hot spot. The crack initiation patterns on the holes of the stringer leg of the angle were found to be very similar to the ones shown in Fig. 11. The only difference is that in this case, cracks are expected to initiate and propagate from the bottom part of the holes. 
Fig. 12(b) shows the hot spot at the angle fillet, assuming a $100 \mathrm{MPa}$ clamping stress. Also shown in Fig. 12(c) are vector plots of the maximum principal stress at the hot spot for a particular load step. Finally, Fig. 12(a) depicts a possible crack initiation pattern at the fillet region. The direction of the maximum principal stress at the fillet hot spot was also found to rotate as the train was traversed over the bridge, by a maximum angle of $35^{\circ}$.

Although the present FE results show that the rivets are the least damaged components of the connection, fatigue cracking in these has been reported on a number of occasions [10,32]. For this reason, fatigue crack initiation patterns based on the present FE results are also presented for the rivets. The region of the hot spot on rivet 1 is shown in Fig. 13(b). Fig. 13(c) shows vector plots of the maximum principal stress at the hot spot, for a particular load step, while Fig. 13(a) depicts a possible crack initiation pattern at the rivet. The direction of the maximum principal stress was found to rotate slightly by a maximum angle of $20^{\circ}$ as the train was traversed over the bridge. As can be seen in Fig. 13(a), the expected crack initiation direction is slightly inclined and will eventually lead to rivet head pop-out. This type of damage pattern was predicted by the FE analyses for all the rivets of the connection.

The fatigue crack initiation hot spots predicted by the FE results are similar to fatigue damage cases observed in recent field investigations in which cracks have been detected in stringer-to-cross-girder connections initiating from either the connection angle fillet or from the rivet holes [9,10,32]. The FEpredicted direction of the cracks initiating in the angle fillet is also in broad agreement with the crack initiation patterns observed in a series of full-scale tests of stringer-to-cross-girder connections [10]. Rivet head pop-outs resulting from cracks similar to the ones predicted by the FE analyses (Fig. 13) have also been detected in the field [9,10,32].

It should be noted that the damage patterns presented in Figs. 11 to 13 are an indication of the crack initiation phase only. These crack orientations would most certainly change as the length of the crack increases. The present model is not able to capture crack development.

Lastly, the results presented in Figs. 9 and 10 should not be viewed as an absolute prediction of the fatigue strength of the investigated connection. The global-local FE analysis was carried out in order to 
investigate the relative criticality of the different connection components (angle fillet, rivet holes, rivets).

The points of crack initiation presented in Figs. 11 to 13 are also points of numerical singularities.

Convergence studies using the global-local FE model revealed that the stresses obtained from the FE analysis do not converge with increasing mesh density. The 'hot-spot stress method', which has been developed in the past, appears to overcome this inconsistency [38, 39]. However, this method has been developed for the fatigue analysis of welded details and its applicability for non-welded details, such as riveted connections, has not yet been established.

\section{Conclusions}

This paper has presented fatigue damage results obtained from FE analyses of a riveted railway bridge. FE modelling techniques were initially verified through benchmark studies on a double-lap joint and a local riveted bridge connection model in terms of stress concentration factors, stress gradients and connection rotational stiffness. These benchmark studies showed good agreement between the FE results and results published in the literature. A refined connection model was subsequently incorporated in the global bridge model. Analyses of the global-local model under the passage of a freight train showed that the rivet clamping stress has a considerable effect on the fatigue damage of the different components of the connection. The most highly damaged regions of the connection were found to be the holes on the stringer leg of the connection angle. By contrast, the rivets were found to be the least damaged components of the connection. When rivet defects were considered, the most damaging cases were found to be the presence of clearance between the rivet shank and rivet hole and the loss of a rivet. Fatigue crack initiation patterns predicted by the FE analyses were found to be in broad agreement with field observations.

Fatigue assessment of connections in large structures will always depend on physical experiments and field observations, as the phenomena and types of behaviour involved are too complex and subject to considerable uncertainties and factors that cannot be accounted for explicitly and quantitatively. However, the numerical modelling methods presented in this paper can offer additional insight and can help in planning and guiding any required tests. 


\section{Acknowledgements}

The work described in this paper forms part of a project supported by EPSRC and Network Rail. The opinions expressed are those of the authors and do not necessarily represent those of the sponsoring organisations. We would like to thank Mr Brian Bell, Network Rail project officer for valuable discussions and feedback.

\section{References}

[1] Kunz P, Hirt MA. Reliability analysis of steel railway bridges under fatigue loading. In: Proc IABSE Colloquium: Remaining Structural Capacity. Copenhagen; 1993, 63-60.

[2] Tobias DH, Foutch DA. Reliability-based method for fatigue evaluation of railway bridges. J Bridge Eng (ASCE) 1997;2(2):53-60.

[3] DiBattista JD, Adamson DEJ, Kulak GL. Evaluation of remaining fatigue life for riveted truss bridges. Can J Civ Eng 1998;25(4):678-91.

[4] Garg VK, Chu KH, Wiriyachai A. Fatigue life of critical members in a railway truss bridge. Earthquake Engineering and Structural Dynamics 1982;10:779-95.

[5] Jahren CT, Rooker JA. Fatigue life study for a railroad bascule bridge. Transportation Research Record 1991;1371:65-74.

[6] Szeliski ZL, Elkholy IA. Fatigue investigation of a railway truss bridge. Can J Civ Eng 1984;11:62531.

[7] Brühwiler E. Measurements for evaluating the remaining service life of a riveted bridge. In: Proc IABSE Symposium: Extending the lifespan of structures. San Francisco; 1995, 1023-8.

[8] Bhavnagri VS. Analysis and testing of an old lattice girder rail bridge. Australian Civil Engineering Transactions 1995;CE37(3):229-39.

[9] Fisher JW, Yen BT, Wang D. NCHRP Report 302: Fatigue and fracture evaluation for rating riveted bridges. Transportation Research Board, Washington DC; 1987.

[10] Al-Emrani M. Fatigue in riveted railway bridges - A study of the fatigue performance of riveted stringers and stringer-to-floor-beam connections. PhD Thesis. Chalmers University of Technology, Sweden, 2002. 
[11]DePiero AH, Paasch RK, Lovejoy SC. Finite-element modelling of bridge deck connection details. J Bridge Eng (ASCE) 2002;7(4):229-35.

[12] Al-Emrani M, Kliger R. FE analysis of stringer-to-floor-beam connections in riveted railway bridges. J Constr Steel Res 2003;59(7):803-18.

[13] Al-Emrani M. Fatigue performance of stringer-to-floor-beam connections in riveted railway bridges. J Bridge Eng (ASCE) 2005;10(2):179-85.

[14] Imam B, Righiniotis TD, Chryssanthopoulos MK. Fatigue assessment of riveted railway bridges. Int J Steel Str (KSSC) 2005;5(5):485-94.

[15] Imam B. Fatigue analysis of riveted railway bridges. PhD Thesis, University of Surrey, 2006.

[16] Imam B, Righiniotis TD, Chryssanthopoulos MK. Connection fixity effects on stress histories in riveted rail bridges. In: Proc $2^{\text {nd }}$ Int conf bridge maintenance, safety and management. Kyoto; 2004.

[17] Philbrick TW, Zodo GW, Schiff SD. Fatigue assessment of through plate girder railway bridges. J Str Eng (ASCE) 1995;121(11):1613-9.

[18]BS 5400. Steel, concrete and composite bridges: Part 10: Code of practice for fatigue. British Standards Institute, London, 1980.

[19] Carter JW. Stress concentrations in built-up structural members. Proc American Railway Eng Association 1952;53:1-34.

[20] ABAQUS. Standard user’s manual version 6.4, Hibbitt, Karlsson \& Sorensen Inc, 2004.

[21] Bursi OS, Jaspart JP. Benchmarks for finite element modelling of bolted steel connections. J Constr Steel Res 1997;43(1-3):17-42.

[22] Vegte GJVD. Numerical simulations of bolted connections: The implicit versus the explicit approach. In: Proc ECCS/AISC workshop: Connections in steel structures V: Innovative steel connections. Amsterdam; 2004.

[23] Shivakumar KN, Newman JC. Stress concentrations for straight-shank and countersunk holes in plates subjected to tension, bending, and pin loading. Technical paper TP3192. NASA; 1992.

[24] Bellett D, Taylor D, Marco S, Mazzeo E, Guillois J, Pircher T. The fatigue behaviour of threedimensional stress concentrations. Int J Fatigue 2005;27(3):207-21.

[25] Timoshenko SP, Goodier JN. Theory of elasticity, New York: McGraw-Hill, 1970.

[26] Wilson WM, Thomas FP. Fatigue tests of riveted joints. Engineering Experiment Station Bulletin 1938;302, University of Illinois. 
[27] Fuchs HO, Stephens RI. Metal fatigue in engineering, New York: John Wiley and Sons, 1980.

[28] Schijve J. Fatigue of structures and materials, The Netherlands: Kluwer Academic Publishers, 2001.

[29] Filippini M. Stress gradient calculations at notches. Int J Fatigue 2000;22(5):397-409.

[30] Akesson B. Fatigue life of riveted railway bridges, Publ. S94:6. PhD Thesis, Chalmers University of Technology, Sweden, 1994.

[31]Zhou YE, Yen BT, Fisher JW, Sweeney RAP. Examination of fatigue strength (Sr-N) curves for riveted bridge members. In: Proc $12^{\text {th }}$ Annual Bridge Conf. Pittsburgh, 1995:102-9.

[32] Al-Emrani M. Stringer-to-floor-beam connections in riveted railway bridges - an introductory study of fatigue performance, Publ. S99:4. Chalmers University of Technology, Sweden, 1999.

[33] Lothers JE. Elastic restraint equations for semi-rigid connections. Transactions of the ASCE $1951 ; 116: 480-94$.

[34] Azizinamini A, Bradburn JH, Radziminski JB. Initial stiffness of semi-rigid steel beam-to-column connections. J Constr Steel Res 1987;8:71-90.

[35] Kishi N, Chen WF. Moment-rotation relations of semirigid connections with angles. J Str Eng (ASCE) 1990;116(7):1813-34.

[36] Roeder CW, MacRae GA, Kalogiros AY, Leland A. Fatigue cracking of riveted, coped, stringer-tofloorbeam connections. Research report WA-RD 494.1, Washington State Department of Transportation, 2001.

[37] Railtrack. RT/CE/C/025, Railtrack line code of practice: The structural assessment of underbridges, Railtrack.

[38] Dong P. A structural stress definition and numerical implementation for fatigue analysis of welded joints. Int J Fatigue 2001;23(10):865-76.

[39] Stress determination for fatigue analysis of welded components. IIS/IIW 1221-93. Abington, Cambridge: Abington Publishing, 1993. 
Table 1 SCF due to pin loading for a double-lap joint ( $P=30 \mathrm{MPa})$.

\begin{tabular}{ccccccc}
\hline & \multicolumn{4}{c}{ Location of stress concentration } \\
\cline { 2 - 7 } & \multicolumn{3}{c}{ Top plate } & \multicolumn{2}{c}{ Middle plate } & \multicolumn{2}{c}{ Bottom plate } \\
\cline { 2 - 7 } & $\mathrm{F}$ & $\mathrm{G}$ & $\mathrm{H}$ & $\mathrm{I}$ & $\mathrm{J}$ & $\mathrm{K}$ \\
\hline [23] & 1.08 & 1.08 & 1.07 & 1.07 & 1.08 & 1.08 \\
\hline Present study & 0.97 & 0.86 & 1.32 & 1.32 & 0.86 & 0.97 \\
\hline
\end{tabular}

Table 2 Stress gradients $Q$ at the edge of the hole for a double-lap joint ( $P=30 \mathrm{MPa}$ ).

\begin{tabular}{ccccccc}
\hline & \multicolumn{4}{c}{ Location of stress concentration } \\
\cline { 2 - 6 } & \multicolumn{2}{c}{ Top plate } & \multicolumn{2}{c}{ Middle plate } & \multicolumn{2}{c}{ Bottom plate } \\
\cline { 2 - 6 } & $\mathrm{F}$ & $\mathrm{G}$ & $\mathrm{H}$ & $\mathrm{I}$ & $\mathrm{J}$ & $\mathrm{K}$ \\
\hline FE results & -0.14 & -0.13 & -0.14 & -0.14 & -0.13 & -0.14 \\
\hline Eq. (6) [27] & -0.18 & -0.18 & -0.18 & -0.18 & -0.18 & -0.18 \\
\hline Eq. (7) [28] & -0.18 & -0.19 & -0.18 & -0.18 & -0.19 & -0.18 \\
\hline$[29]$ & -0.20 & -0.20 & -0.20 & -0.20 & -0.20 & -0.20 \\
\hline
\end{tabular}

Table 3 Rotational stiffness according to different sources.

\begin{tabular}{cc}
\hline Source & $\begin{array}{c}\text { Rotational stiffness } \\
(\mathbf{k N} \cdot \mathbf{m} / \mathbf{r a d})\end{array}$ \\
\hline FE (50 MPa clamping stress) & $1.92 \times 10^{4}$ \\
\hline FE (200 MPa clamping stress) & $2.02 \times 10^{4}$ \\
\hline$[32]$ & $1.00 \times 10^{5}$ \\
\hline$[33]$ & $5.50 \times 10^{4}$ \\
\hline$[34]$ & $4.35 \times 10^{4}$ \\
\hline$[35]$ & $2.86 \times 10^{5}$ \\
\hline$[36]$ & $1.42 \times 10^{3}$ \\
\hline
\end{tabular}




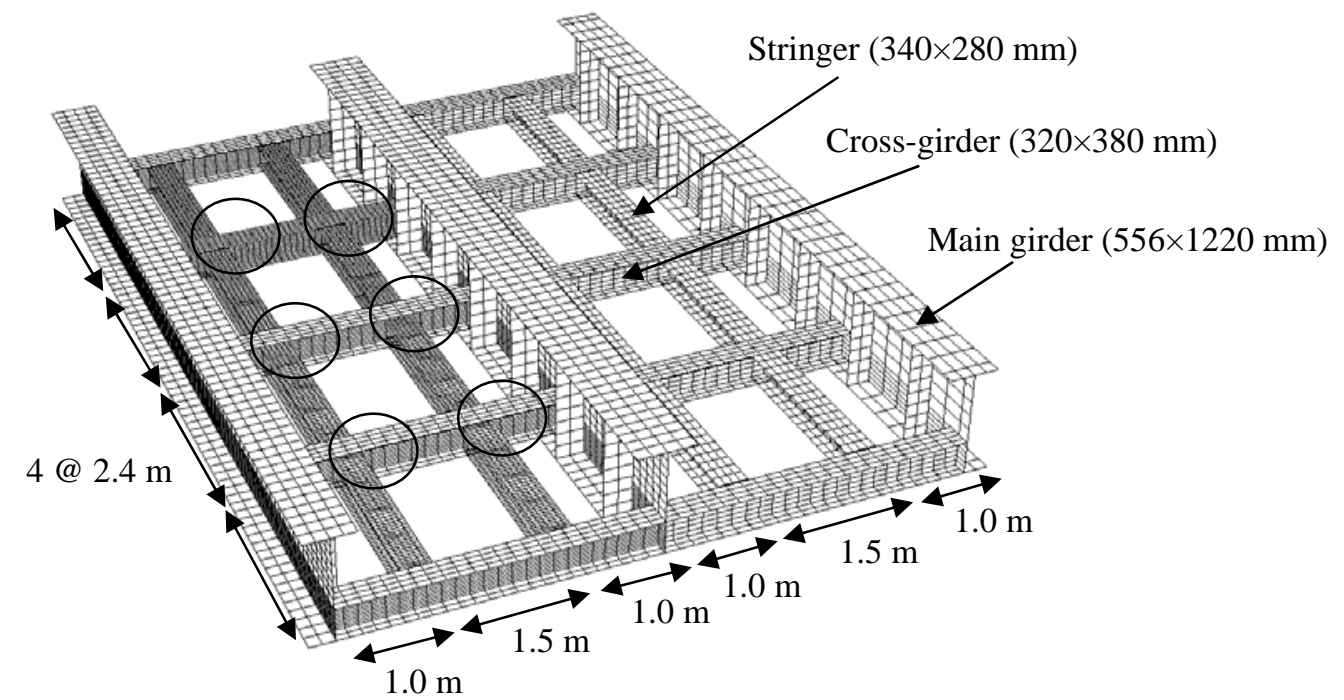

Figure 1 Global FE model of the bridge and relevant dimensions.

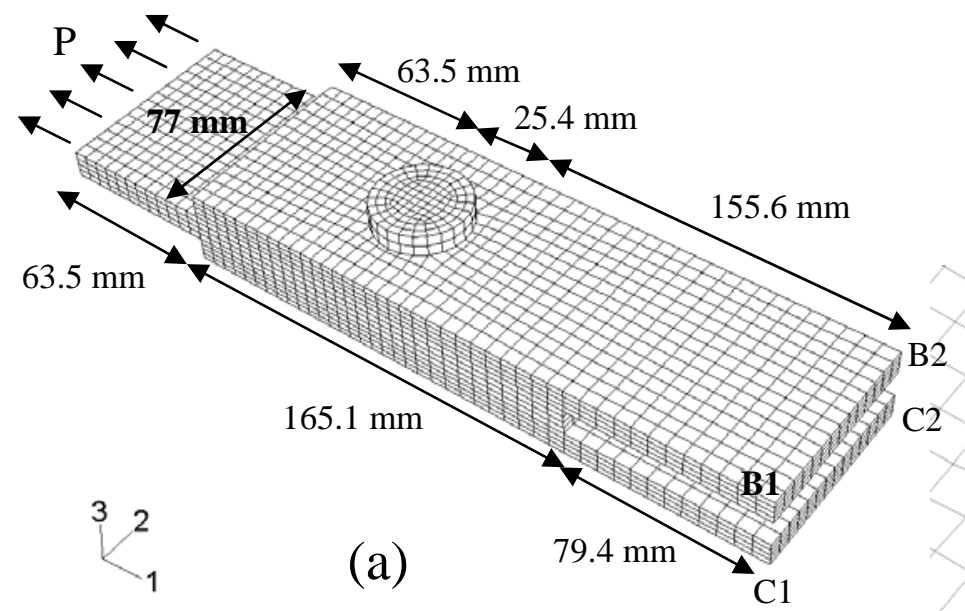

G,H.

$\mathbf{I , J}$.

K.

(b)

Figure 2 (a) Finite element model of a riveted double-lap joint (b) locations under consideration. 


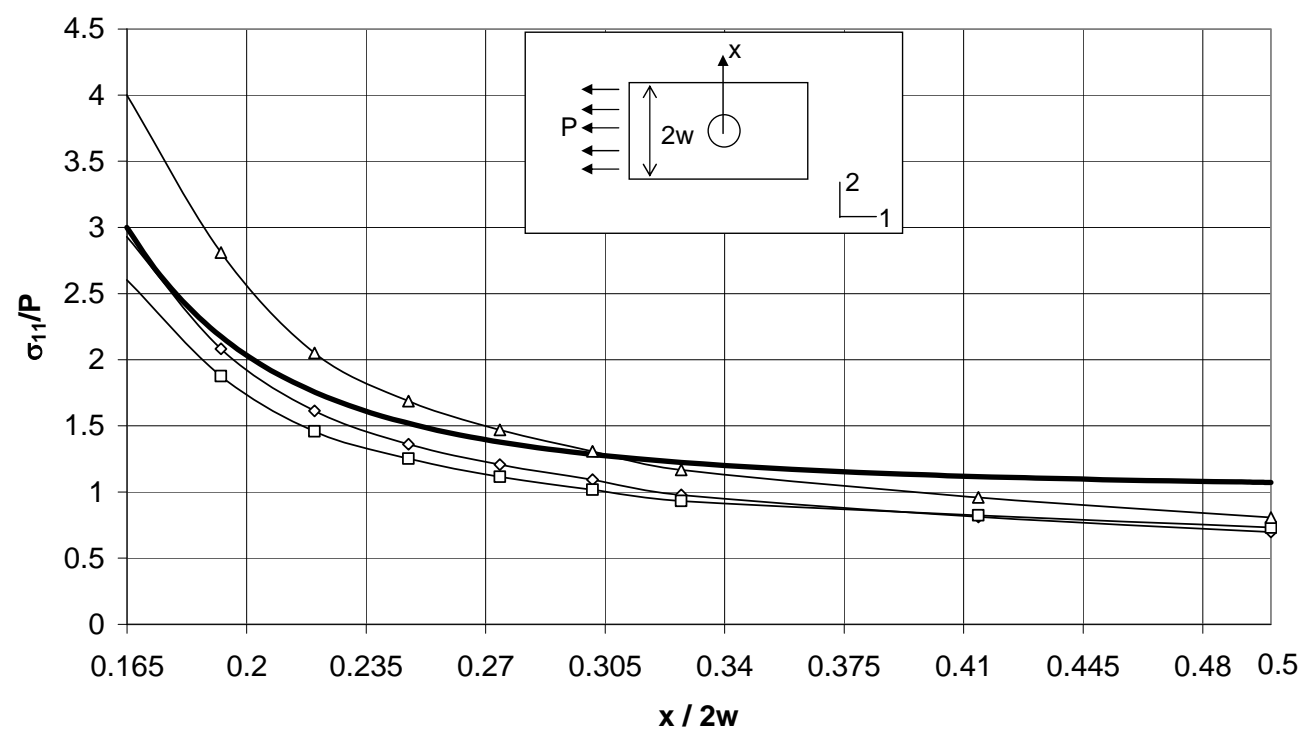

$\multimap F$ and $K \neg-G$ and $\mathrm{J} \neg-\mathrm{H}$ and $\mathrm{I} \longrightarrow$ Reference [25]

Figure 3 Normalised longitudinal stress distribution along the plate width of a double-lap joint $(\mathrm{P}=30$ $\mathrm{MPa})$.

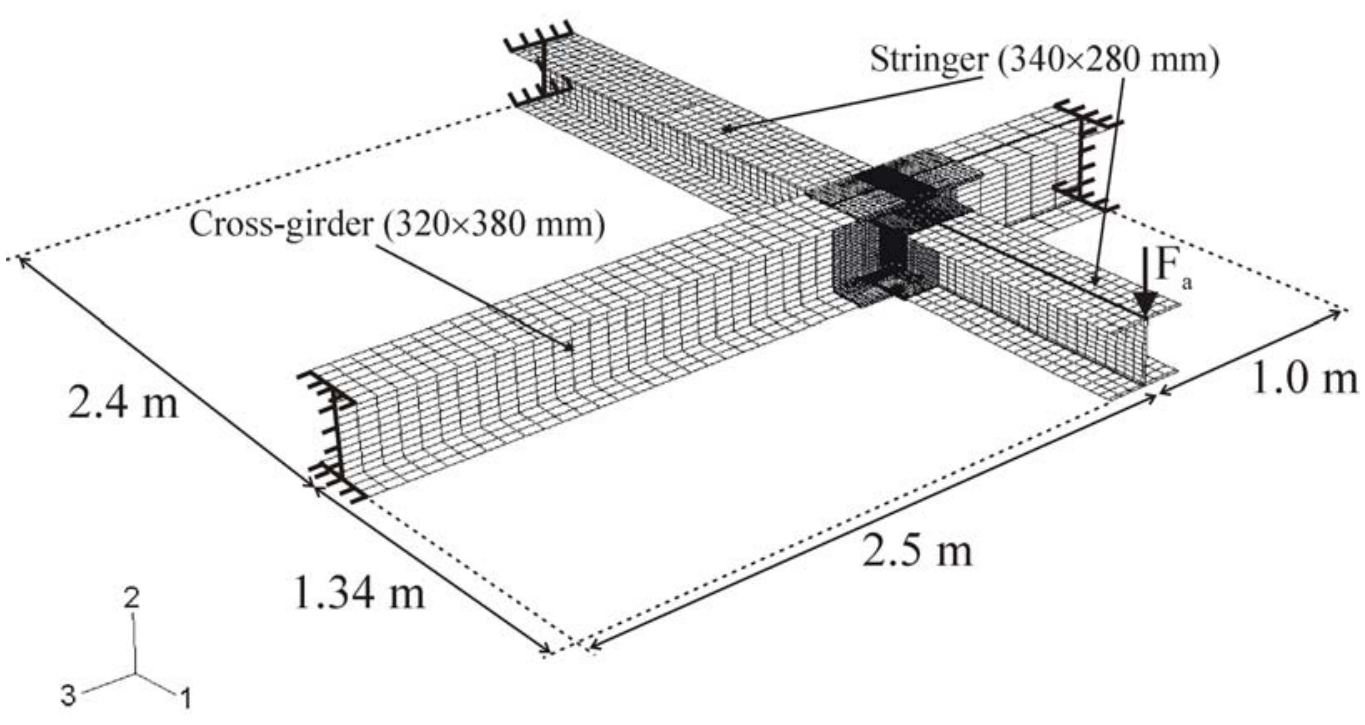

Figure 4 Finite element model of the stringer-to-cross-girder connection. 


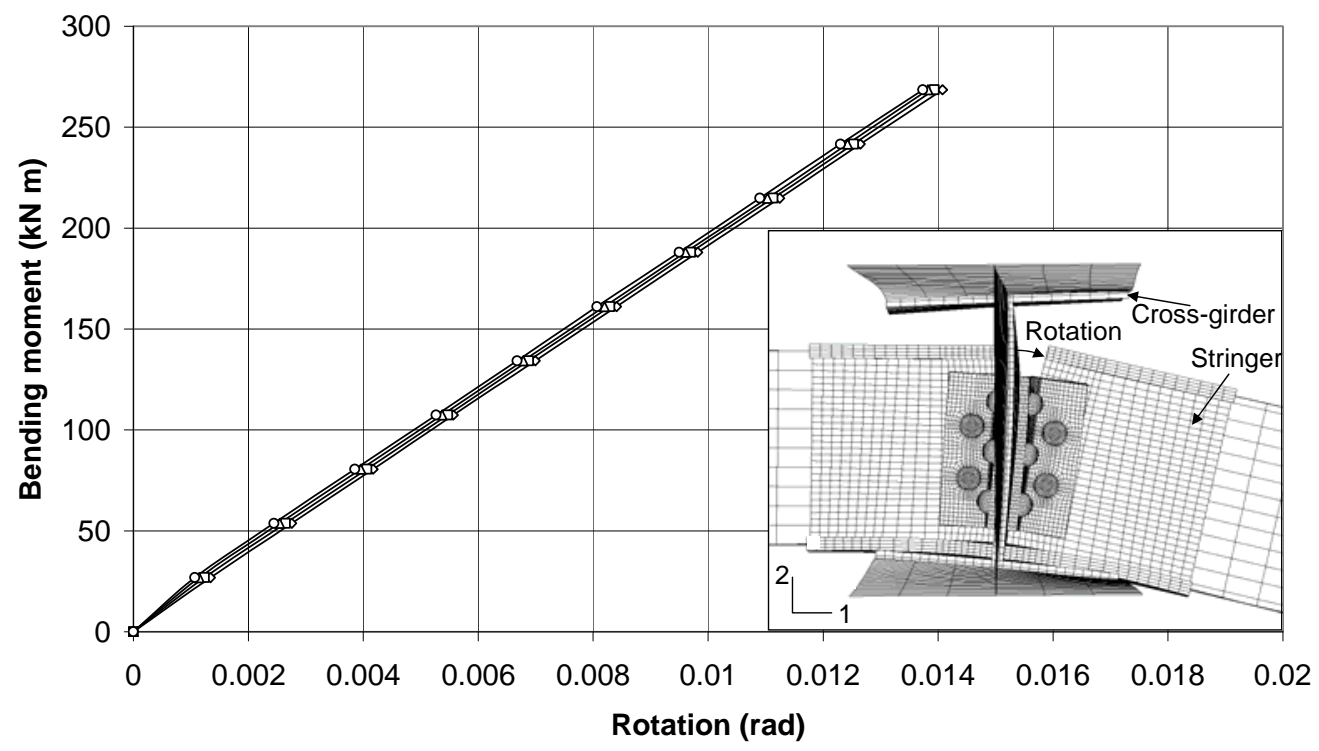

$\leadsto-\mathrm{C} 50-\square-\mathrm{C} 100 \rightarrow \mathrm{C} 150 \multimap \mathrm{C} 200$

Figure 5 Moment-rotation behaviour of the stringer-to-cross-girder connection.

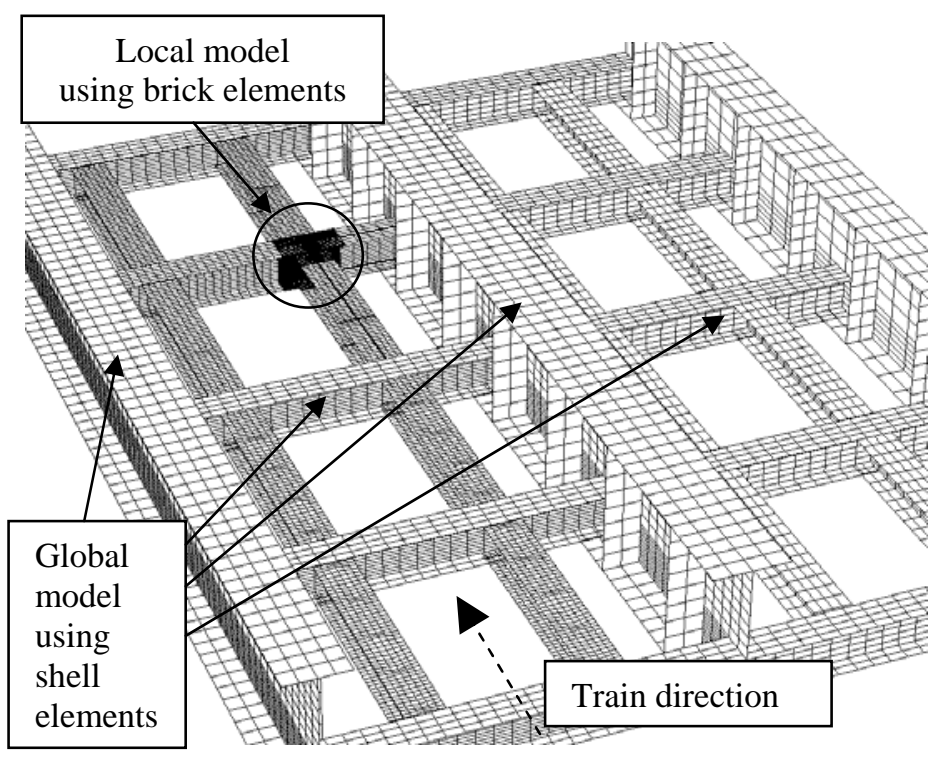

Figure 6 Global-local FE model of the riveted bridge. 


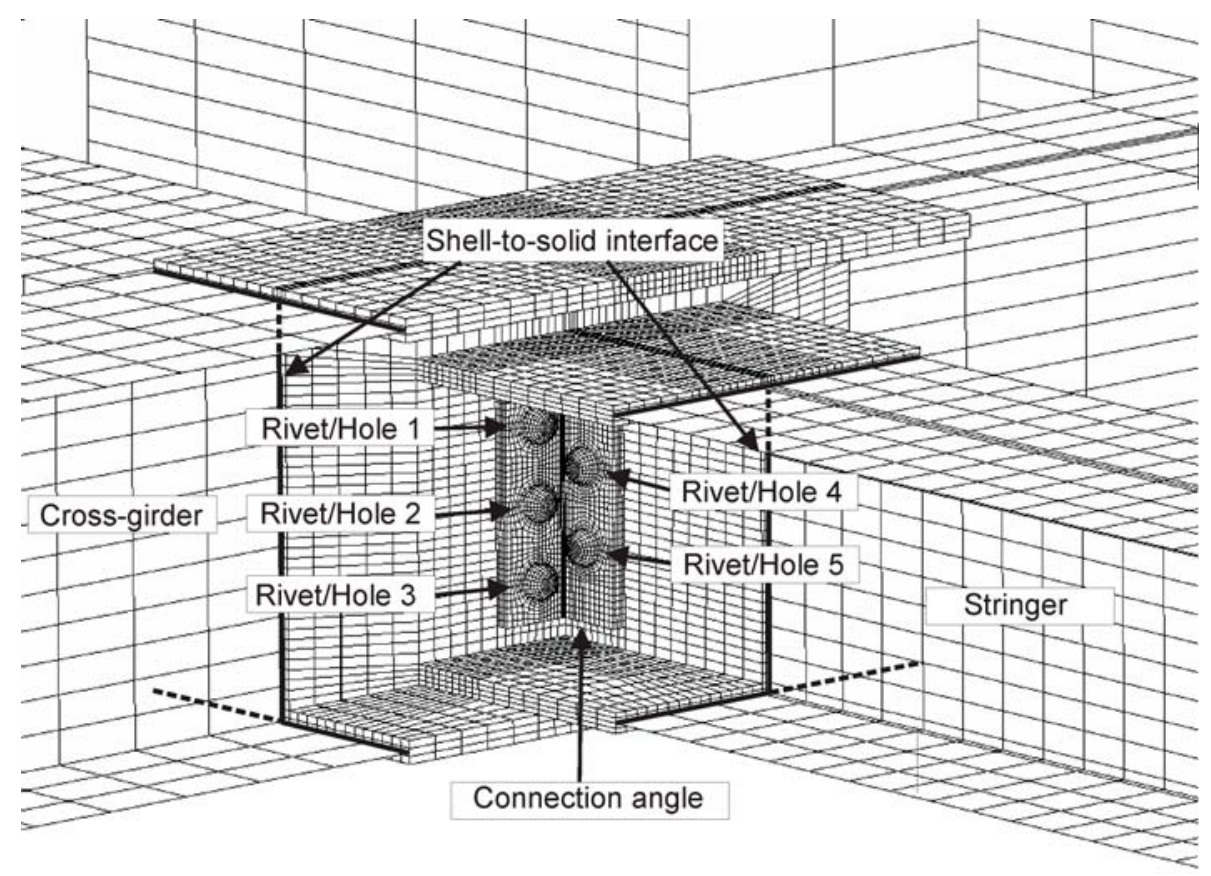

Figure 7 Close-up view of the global-local FE model at the connection region.
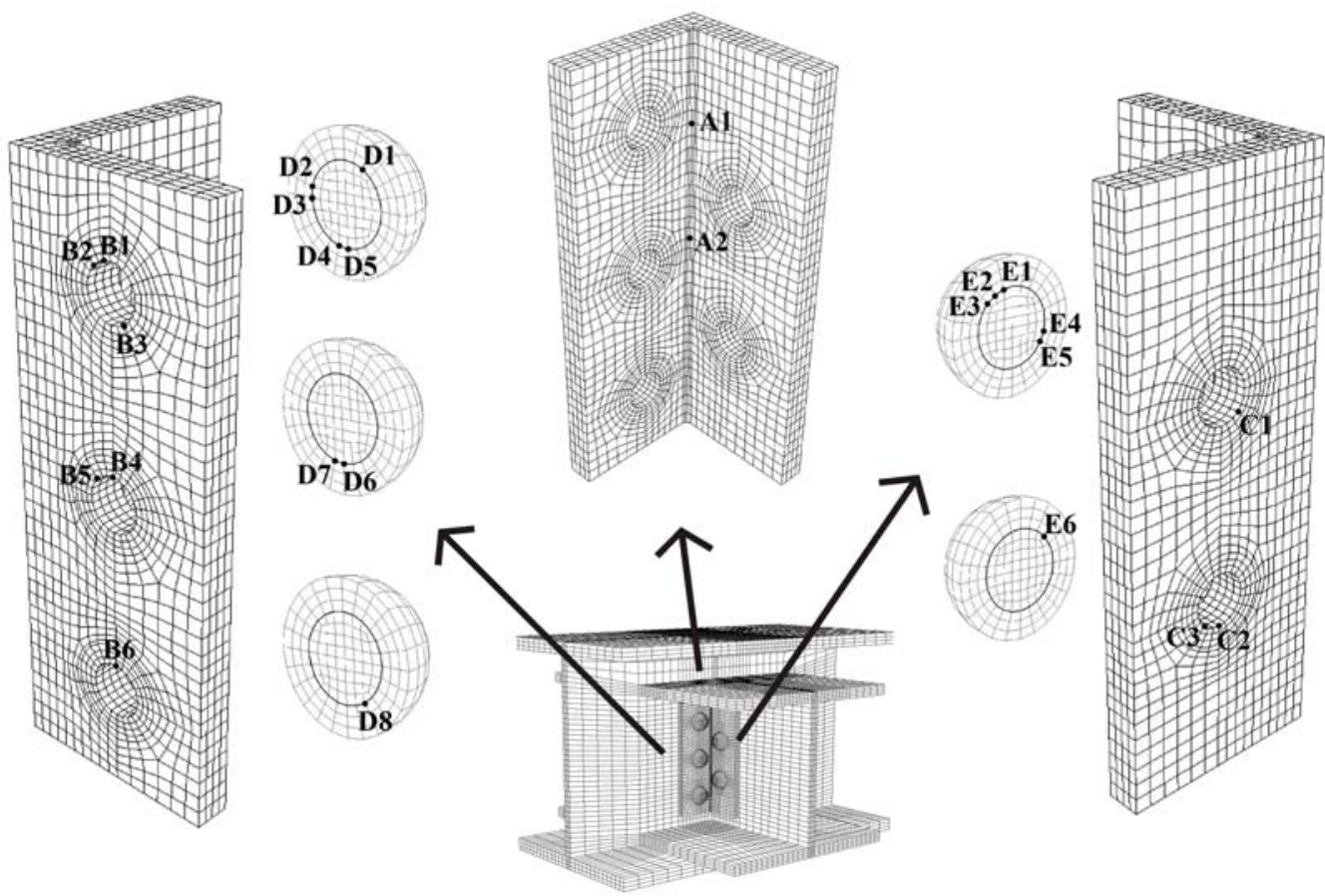

Figure 8 Hot spot locations at different parts of the stringer-to-cross-girder connection. 


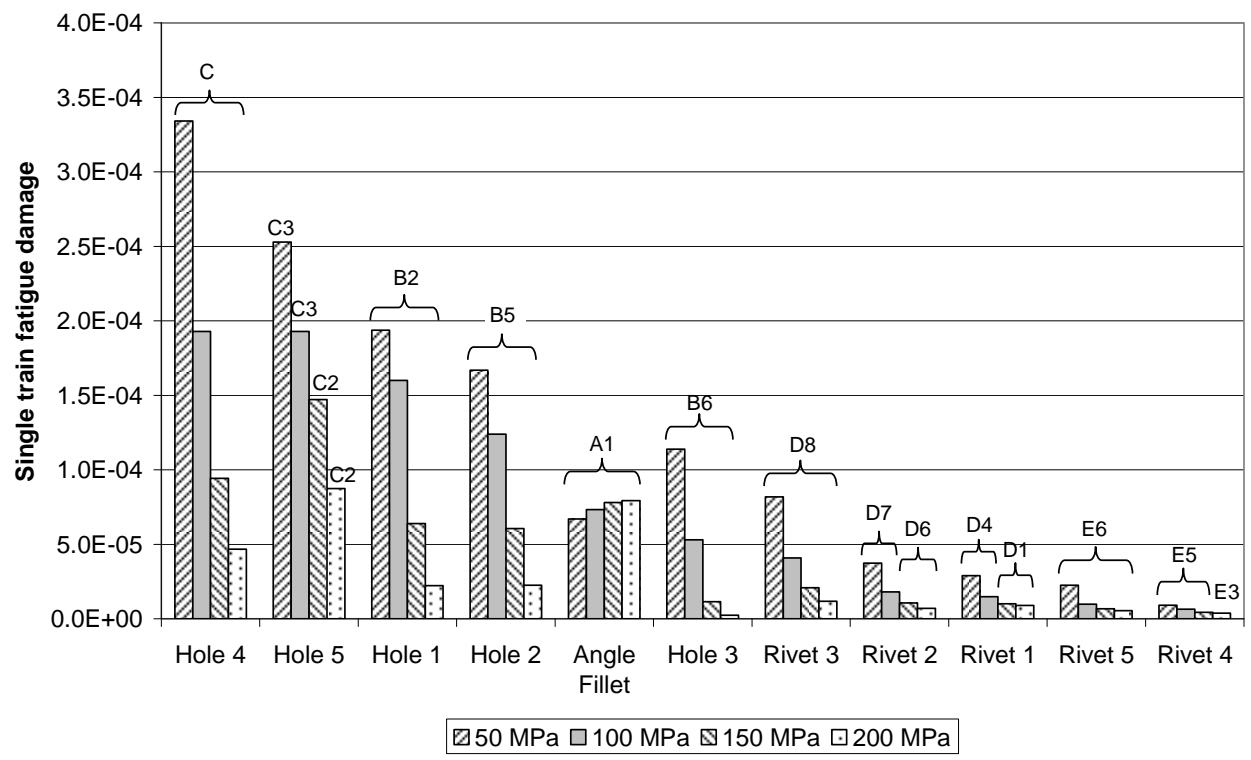

Figure 9 Effect of rivet clamping stress on connection damage.

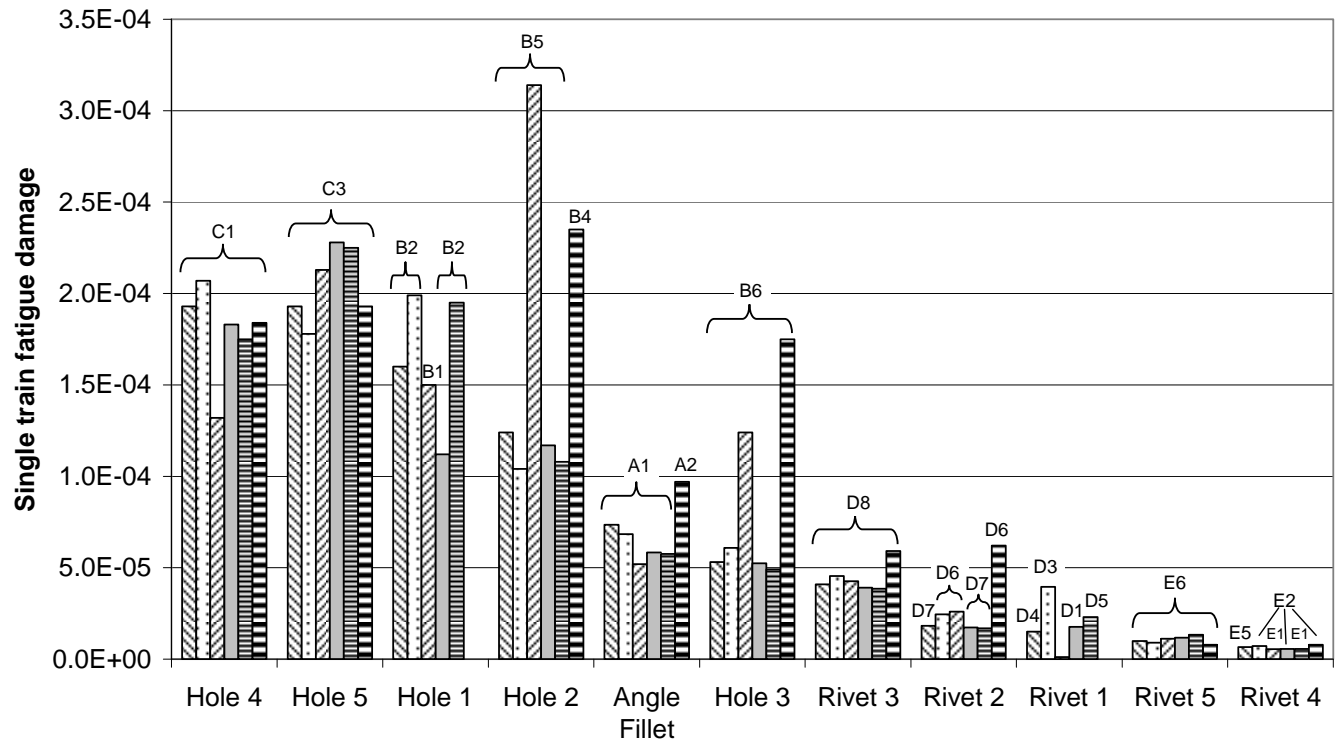

⿶ No Defects (100 MPa) $\square$ Loss of clamping $\square$ Rivet clearance $\square$ Small rivet head 目 Rivet head offset $\boxminus$ Rivet loss

Figure 10 Effect of various rivet defects on fatigue damage. 

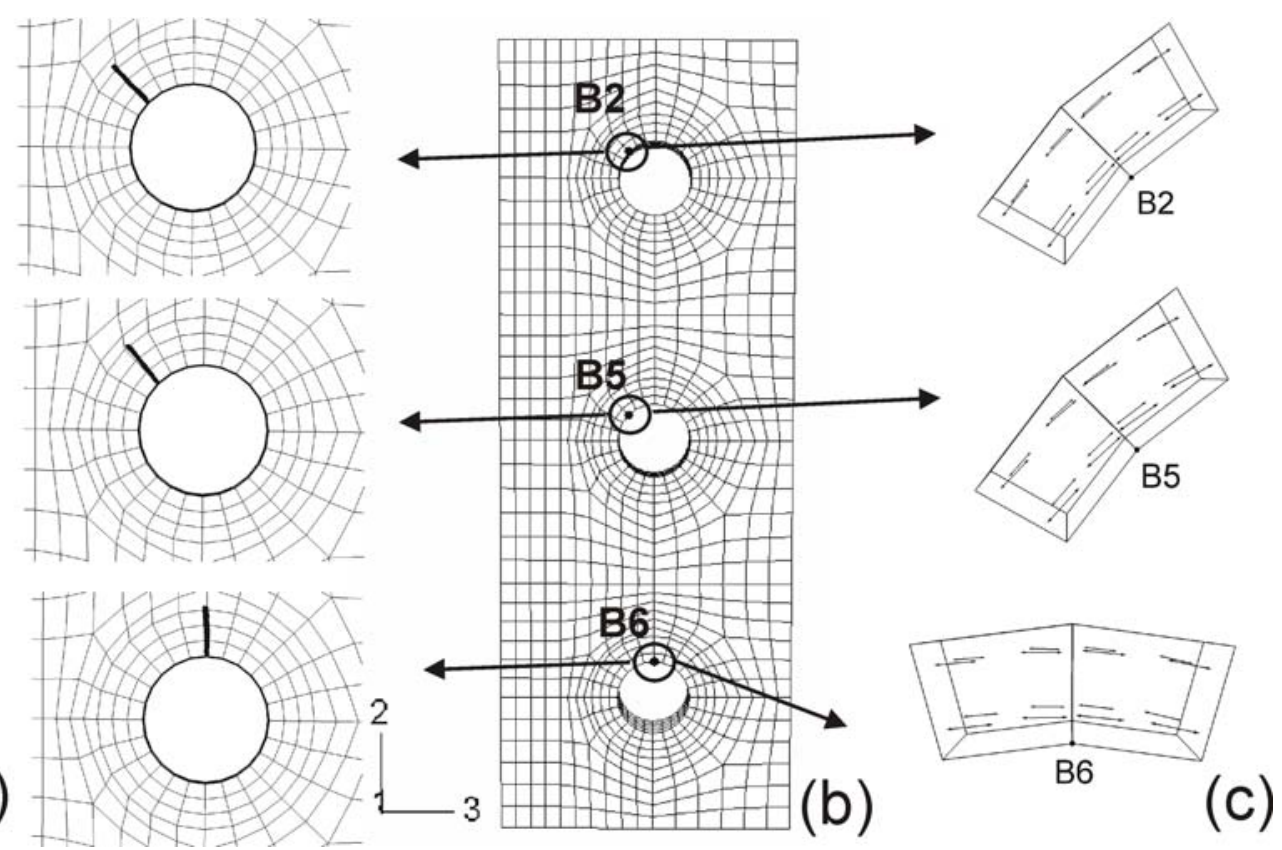

(a)

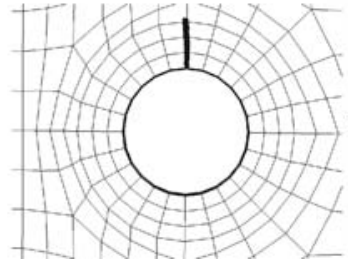

Figure 11 Cross-girder side of connection angle (clamping stress =100 MPa) (a) Possible crack initiation patterns (b) Fatigue crack initiation hot spots on holes (c) Vector plot of maximum principal stresses.

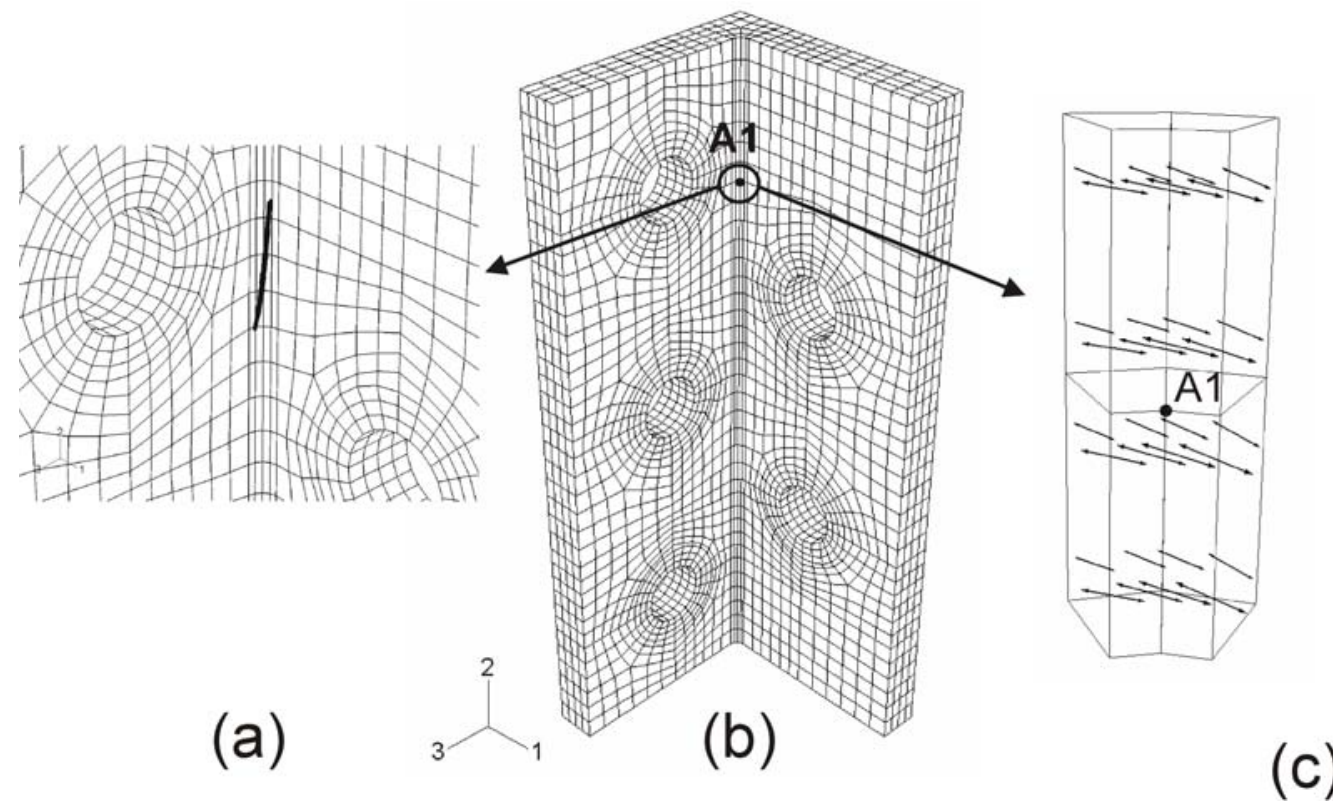

Figure 12 (a) Possible crack initiation pattern on angle fillet (b) Fatigue crack initiation hot spot (clamping stress=100 MPa) (c) Vector plot of maximum principal stress. 


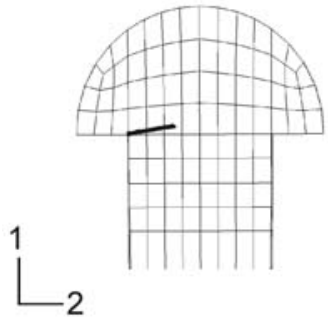

(a)

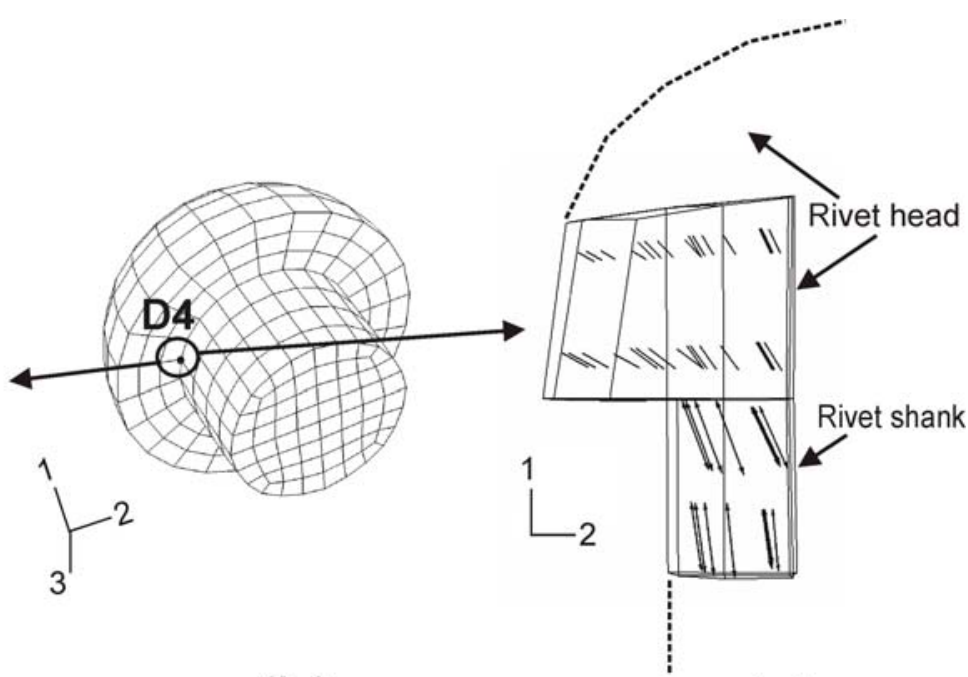

(b)

(c)

Figure 13 (a) Possible crack initiation pattern on rivet 1 (b) Fatigue crack initiation hot spot (clamping stress=100 MPa) (c) Vector plot of maximum principal stresses. 